\title{
Complementarity in a Digital Global Production Network: A Case Study
}

\author{
Joel Bigley* \\ USA \\ *Corresponding Author: Joel Bigley, USA

\begin{abstract}
This case study looks at the impact of aspects of diversity on entrepreneurial collaboration within a multi-national enterprise. Effective organizations create value for clients by leveraging a portfolio of talent distributed globally. To realize sustained corporate advantage in global markets, MNE's must have a timely and diverse global capability. While cultural diversity exists locally within facilities, it also exists between facilities in the global production network (GPN). A single case study is used to discuss aspects of culture that allow for complementarity within a global organization striving to succeed in a competitive market.
\end{abstract}

Keywords: Alignment Structures; Talent Diversity; Scaffolded Collaboration; Ethno-Geographic Components; Culture Distribution Shifting; Cultural Agility

\section{INTRODUCTION}

In this paper the author will discuss three aspects of culture that when aligned allow for complementarity within a global organization striving to succeed in a competitive market. The author uses an empirical case to describe a theory of exploited complementarity. In order to make this theoretical contribution the author will discuss a sequence of topics and then relate them to the case. Following the introduction to the context of the case study, a literature review presents the following contributing cultural elements; cultural distance, multi-cultural, culture distribution shifting, and cultural agility. In order for an organization with business or functional units that are not fully integrated to collaborate, the diversity within the overall construct must be understood and then its complementarity must be exploited (Serrano-Bedia, López-Fernández, \& García-Piqueres, 2017). Consequently, the author will first discuss four aspects of organization diversity; ethos, geographic, ethnic, and personal. With this understanding the integration of diversity can be approached. Secondly, the author discusses the elemental unit of culture in an organization; a worker that makes decisions. Each worker makes a contribution to the diversity in the organization. The components of diversity are housed within a worker, there for, these components must be understood. With the elements of the organization and the worker better understood, the author will then discuss the interaction between the two. This is followed by a discussion regarding the alignment within an organization and mechanisms to increase a singleness of purpose, or one-ness. Lastly, the author will discuss the need for the now aligned organization to shift together. Sustained corporate advantage is dependent on this ability. Visuals are used to illustrate this theory of exploited complementarity. In sum, the discussion begins with an understanding of an unintegrated grouping of organizations to the synchronous movement of a competitive organization aligned through the exploitation of its complementarity.

This case study will reference the lessons learned from the GPN used by Signal Corp, a pseudonym for a real organization. A constellation of geographical locations of the case MNE is illustrated in Figure 1. The author will leverage both local and global diversity across locations by presenting the structural alignment elements that minimize collisions between global units. The author will focus on integrative structures that enable organizations to meet client demands. Collaboration in a global context includes an optimized portfolio of the needed talent deployed at the right time in the right place resulting in optimal organizational effectiveness, or complementarity. Evidence of a winning recipe is seen within Signal Corp (fictitious name) in the form of effective interaction patterns that cross cultural lines both between locations and within locations. Each stakeholder approaches a goal from a different cultural vantage point; however, aligned global collaboration influences profitability. 


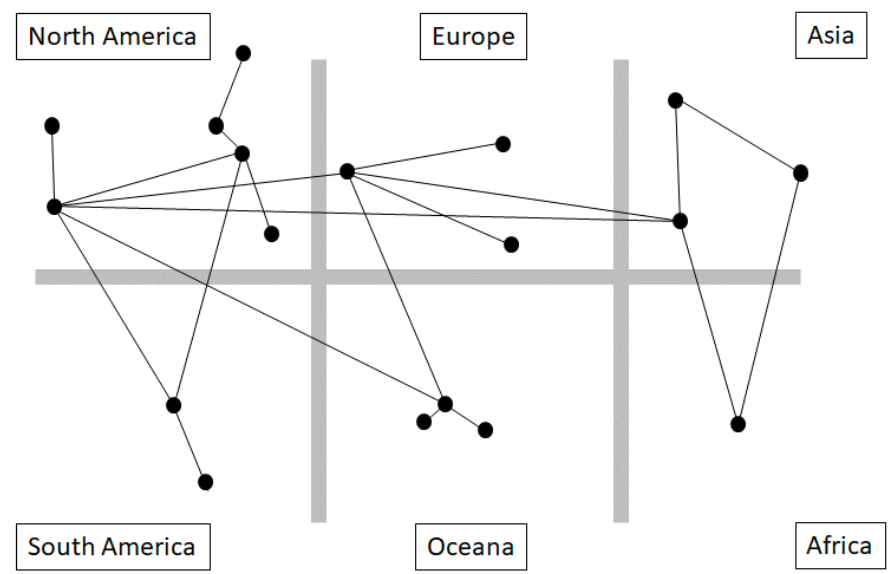

Figure 1. Global production network. This figure maps a network of dependent operational facilities in a global context.

Signal Corp is a leading high volume distributor of customized digital media packages. It has operations that cover a changing global market. It has a dominant market position it intends to keep in an industry that is subject to significant competition. In the case of Signal Corp, all of the available talent is influenced by an amalgamation of cultures that where created over time through acquisitions, integrations, expansions, or organizational change. There is no assumption that there is a homogenous ethos within the interrelated global network of business units. Neither is there a lack of variability in the conjoined talent present. In fact, it is varied throughout the organization as described in Figure 2.The organizational ethos has been influenced by cultural norms passed on by leadership structures each of which has had a varied degree of penetration. This group culture is also a bottom-up phenomenon that is the result of established routines blended over time. Specifically, the resulting cultural mix may be influenced by geographic location (Geo \#), ethnic impact (Eth \#-\#), personality $(\mathrm{P \#})$, and the current organizational ethos (Org \#).This collaborative organization influenced by and dependent on conjoined talent must achieve organizational effectiveness in a dynamic marketplace to thrive.

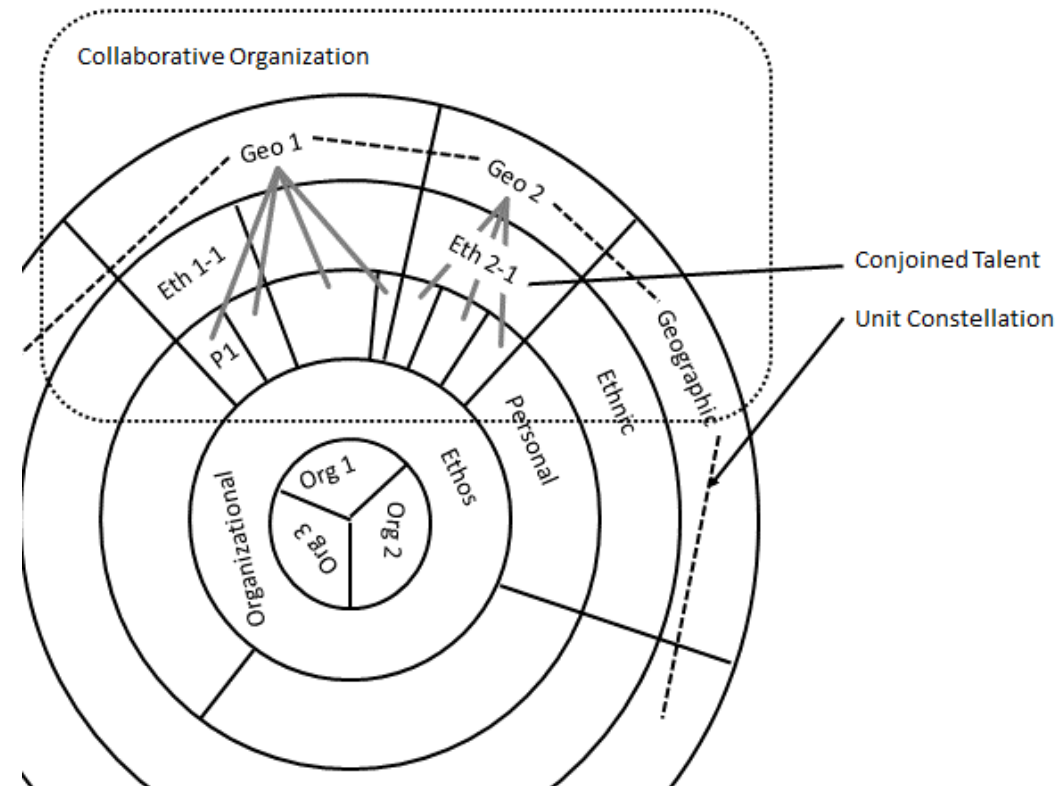

Figure 2. Organizational diversity and effectiveness. This figure maps the amalgamation of organizational cultures to leadership, personal, and ethno-geographic components.

\section{LITERATURE REVIEW}

\subsection{Cultural Elements}

The cultural elements of engaged individual actors vary according to a distribution that may be influenced by the weighting of influential attributes. These attributes determine choices and reactions. Variation between cultures, when accommodated, mandates at least a partial transition from one 
distribution to another. Culture based distributions can be described relative to ethnic groups, nations, organizations, and actors as influenced by occupations, genders, generations, or social classes. For example, Hofstede (2011) suggests that there are six cultural dimensions; process versus results oriented, job versus employee oriented, professional versus parochial, open versus closed systems, tight versus loose control, and pragmatic versus normative while Costa and McCrae (1992) empirically determined five personality dimensions of individuals including neuroticism, extraversion, openness to experience, agreeableness, and conscientiousness. While a number of models exist, purposive adaptation, or alignment, is the accommodating shift that a leader makes when they move their individual distribution of attributes closer to another person's so as to understand and influence them. This attribute distribution can apply to ethnic groups, nations, organizations, occupations, genders, generations, social classes, or individuals. The weighting of the individual attribute values, as described by their height in the distribution, can be influenced by how deeply rooted they are, how required they are within a lived environment, how they relate to an ability to have an income, and how socially acceptable they are for purposes of inclusion. "Values are the tendency of a group to prefer certain states of affairs over another (Hofstede\& Hofstede, 2001, p.5)."

Culture is a collective phenomenon that is interconnected and variably influential in an environment, an organization, or a person. Within each collective, cultural diversity is exhibited by engaged actors. Cultural components, or collective mental programming, are acquired from family, school, occupations, and memberships in groups. Some of these components are exchangeable, or learnable, while others are more difficult to acquire. Personal values, whether transferred or learned from experience. These values drive behavior and reactions to stimuli, and include the perception of how people react to stimuli in the environment.

These cultural differences result in distinct answers to the same question as sense-making varies within the same general situation (Kluckhohn, 1962). Parsons and Shils (1951) suggested that all action is determined by choices between pairs of alternatives and then suggested five patterns of variables including affectivity, self-orientation, universalism, ascription, and specificity. They suggested that these choices are present at the personal, group, and cultural levels. Kluckhohn and Strodtbeck (1961) distinguished communities based on five value orientations including human nature, biological nature, time, activity, and relationships. "Culture is the collective programming of the mind that distinguishes the members of one group or category of people from others (Hofstede, 2011, pg. 3)." These collective phenomena are interconnected and variably influential, important, or weighted for significance in an environment, an organization, or a person's individual psyche as illustrated in Figure 3. If an actor is appropriately positioned and led, their cultural dimensions are in a force field that has attributes that either enhance or diminish complementarity in an interconnected organization. Coaching, timely and accurate placement, and the influence of leadership that is aligned can be used to leverage the complimentary impact of each individual worker. Ultimately, these three dimensions affect collaboration between local and global team members.

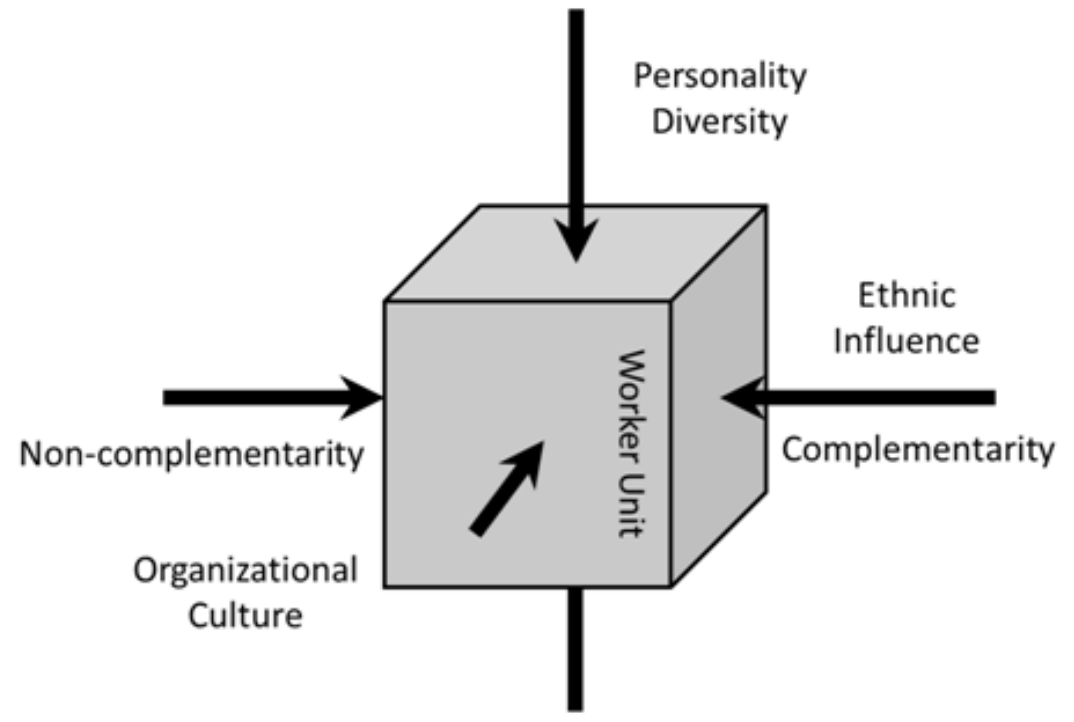

Figure 3. Individual complementarity force field. This figure maps the three aspects of culture and illustrates the impact of complementary and non-complimentary aspects. 


\subsection{Cultural Distance}

Cultural distance, or foreignness, is measured by the differences in cultural values and communication styles between groups or individuals. This distance could be described by the differences between what Hofstede, Hofstede, and Minkov (2010) described in their six parameters including power distance (related to human inequality), uncertainty avoidance (stress of the unknown), individualism versus collectivism (individual integration into groups), masculinity versus femininity (the gender based division of emotional roles), long term versus short term orientation (the choice of where to focus efforts), and indulgence versus restraint (controls regarding human desires). These differences also describe organizational cultures and personalities of individuals, and so is universal across contexts. The confluence of attributes with varied linkage strength, as illustrated in Figure 4, have direct or indirect interaction. This interaction zone is where organizational effectiveness or dissonance occurs.

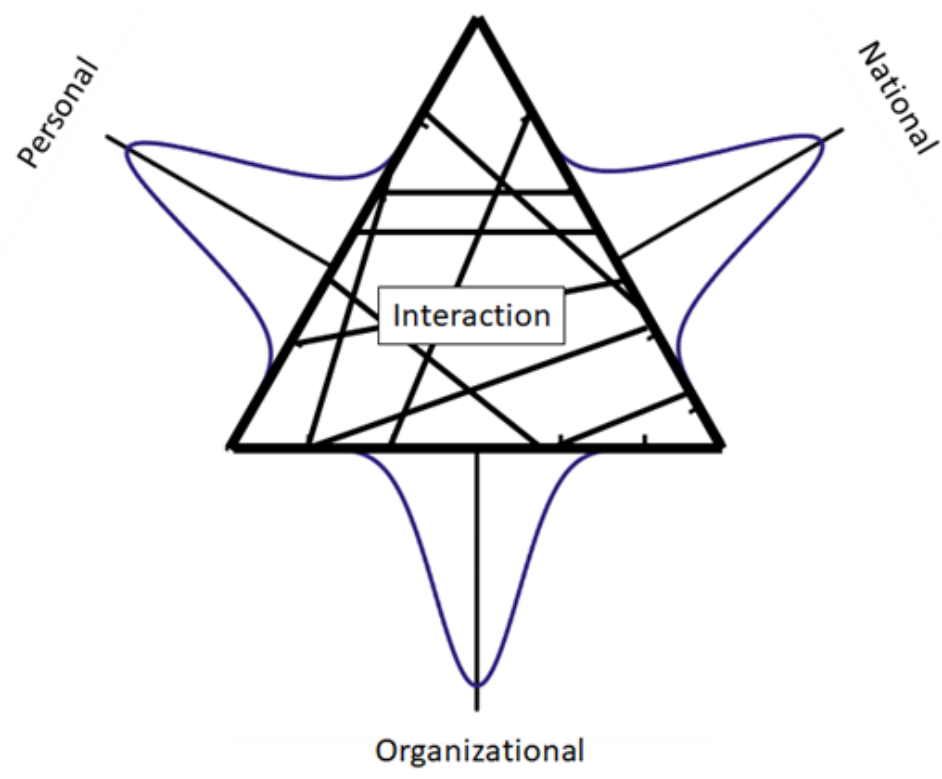

Figure 4. Dimensional attribute interaction. This figure illustrates the interaction between the distributions of the three categories of culture within an organization.

\subsection{Multi-Culturals}

People have a multi-variate distribution of cultural attributes embedded in their consciousness. This consciousness is influenced by knowledge about values, norms, and beliefs of the cultures included in their attribute schema. Multi-cultural influencers are becoming more of a factor in organizations as cultures continue to blend. Multicultural teams perform more work today in global organizations than ever before. They can improve organizational effectiveness if deployed with minimal friction (Cox, 1993; Galbraith, 2000; Kirchmeyer \& McLelland, 1991; Kirkman \& Shapiro, 2001). Friction is natural with diversity, hence the need for effectiveness augmentation through alignment structures.

The biggest challenges with cross-cultural team effectiveness is solving the right problems effectively, encouraging a free flow of factual information, maintaining mutual respect, and implementing a suitable leadership style. Multi-cultural leaders need to be able to address these challenges so that multi-cultural teams can be a meaningful force in a global organization. While desired outcomes are typically known across the MNE, the starting position of stakeholders is varied. Leaders can understand the base position of stakeholders and initiate agile responses to situational cultural issues. Broad-based multi-culturals have cognitively complex cultural representations and are better able to adapt their behavior to cross-cultural settings (Benet-Martinez \&Haritatos, 2005). Multi-culturals also have special knowledge of common and unique beliefs and values. They understand role repertoires and communication protocols and so can plot the path to success.

Given that some level of conflict may be needed to create focus and motivation, multi-cultural intelligence is required to span boundaries so that problems can be solved efficiently and so that global teams can move forward. A complex multi- and mono-cultural schema can be represented as shown in Figure 5. An aligned collective would have distributions that largely overlap. 

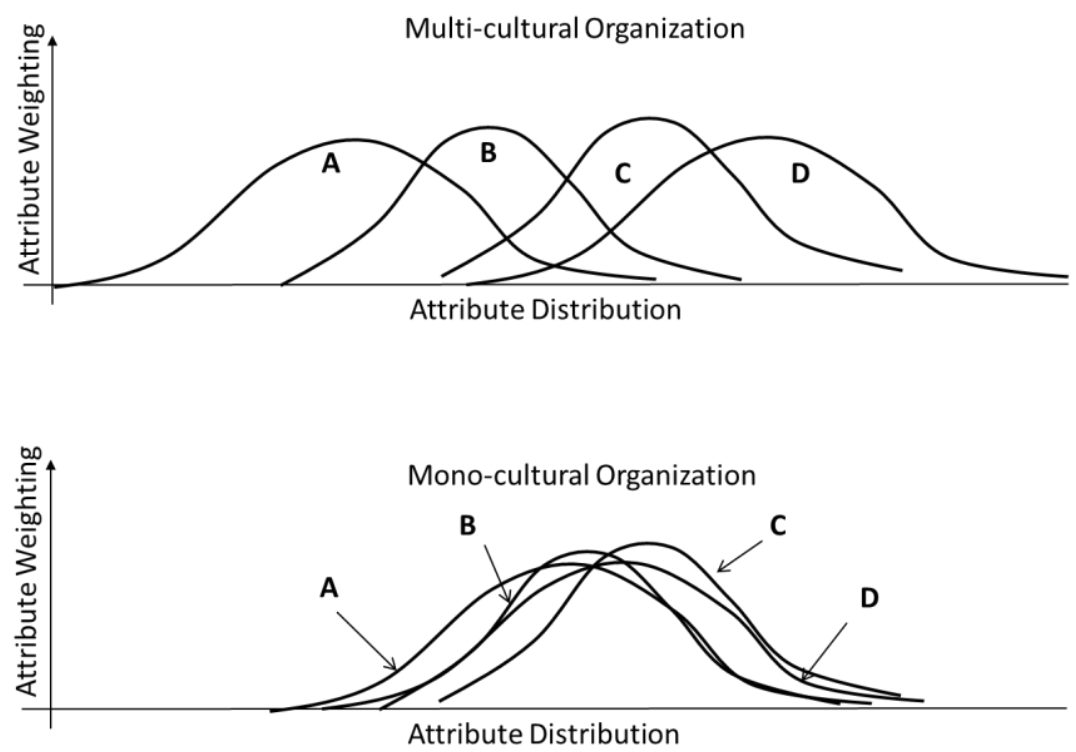

Figure 5. Multi-versus mono-cultural distribution schema. This figure illustrates the distributions of culture in a unified versus fragmented organization.

A multi-attribute schema is a complex cultural representation that is influenced by heritage, endured experience, and isolation. In locations where there is cultural diversity, the complexity of achieving team cohesion, inclusion, and integration is a challenge for global leaders (Stevens, Plaut, \& SanchezBurks, 2008).Competence is described by Sundberg and his colleagues (1978) as the personal characteristics (knowledge, skills, and attitudes) that lead to achievements that have adaptive payoffs (by assessing motives, demands, and resources) in significant environments. The definition of multicultural competence would need to relate multicultural capabilities with contextual and situational demands. It would also need to include the ability to cope and the ability to pursue interests effectively in a known environment. The definition of multi-cultural capability would need to refer to a persons' ability to draw upon cultural knowledge, apply cultural metacognition, adapt, and effectively communicate so as to ensure success regarding an organizational outcome.

\subsection{Cultural Distribution Shifting}

Cultural distribution shifting (CDS) is a unique ability that allows multi-culturals to competently influence, interact with, and achieve results while cognitively operating in an attribute distribution that is shifting and changing shape based on internal and external influences. Multi-cultural agility (MCA) is an aspect of acculturation that is the ability to operate cognitively in a current distribution while pushing the distribution to an incremental configuration that is both predictively needed and aligned with a vision. The desired cultural profile is ultimately required, and so is the catalyst for successful and timely organizational change. Multi-cultural cognition, or cultural intelligence, is the ability to effectively interact with others who are culturally different (Rathje, 2007). This requires an understanding of reasoning and thinking needed for effective understanding and the execution of interaction strategies.

An understanding of one's own culture is important for an understanding of potential opportunity or conflict. Both verbal and non-verbal attributes come to bear on a situation that must be influenced or accommodated to achieve desired outcomes. Capable multi-cultural leaders can leverage their metacognitive capabilities to transpose their effectiveness to other environments described by different cultural distributions. These capabilities can be transferred to other settings; individual interaction and group interaction for example. These are aspects of dynamic cultural distribution shifting and interactions between distributions that must be timely. While the spatial extent of the distribution may be broad or narrow, knowledge of the content, and the systemic cognitive processing of it, are critical capabilities. These are visible in pattern recognition, responses to situational cues, strategy formation, and decision making ability.

Multi-cultural effectiveness (MCE), therefore, becomes a unique construct for global leaders. Culture is constructed of history, institutions, rituals, and daily practices that influence behavior and thought. It is highly relevant to self-image and therefore highly accessible to memory (Markus, 1977; Nowak 
et al., 2000). For example, within and individual or an organization, the removal of a single ritual might compromise the ability to achieve goals. A leader must then use a broad range of culture specific knowledge to understand valued rituals in order to enact cultural frame shifting. This allows actors to decode and comprehend the behavior of others in relation to their own behavior. Ultimately, MCA is needed to drive the strategic alignment of behaviors that harness the complementarity of a diverse workforce intended to achieve a global objective.

While it is unlikely that a leader can avoid the frustration from miscommunication, misattribution, or misevaluation during overt verbal and nonverbal interaction in a variety of contexts, a leader with the ability to become aware of such frustration may be able to recover and reduce tensions through behavioral adaptation. Cultural distribution shifting requires awareness, the determination of a course of action, and the ability to execute while being flexible and capable of course correction. For example, cultural norms change quickly in developing countries, especially within the younger age demographic. Therefore, the attributes of a leader needs to be aligned with the intended organizational culture as opposed to the less relevant current culture. Individuals that are not able to shift to the new culture may become a liability to the organization and its objectives as depicted. A leader may need to span attribute distributions initially, but ultimately would need to exhibit an attribute repertoire needed for the envisaged organization as depicted in Figure 6.
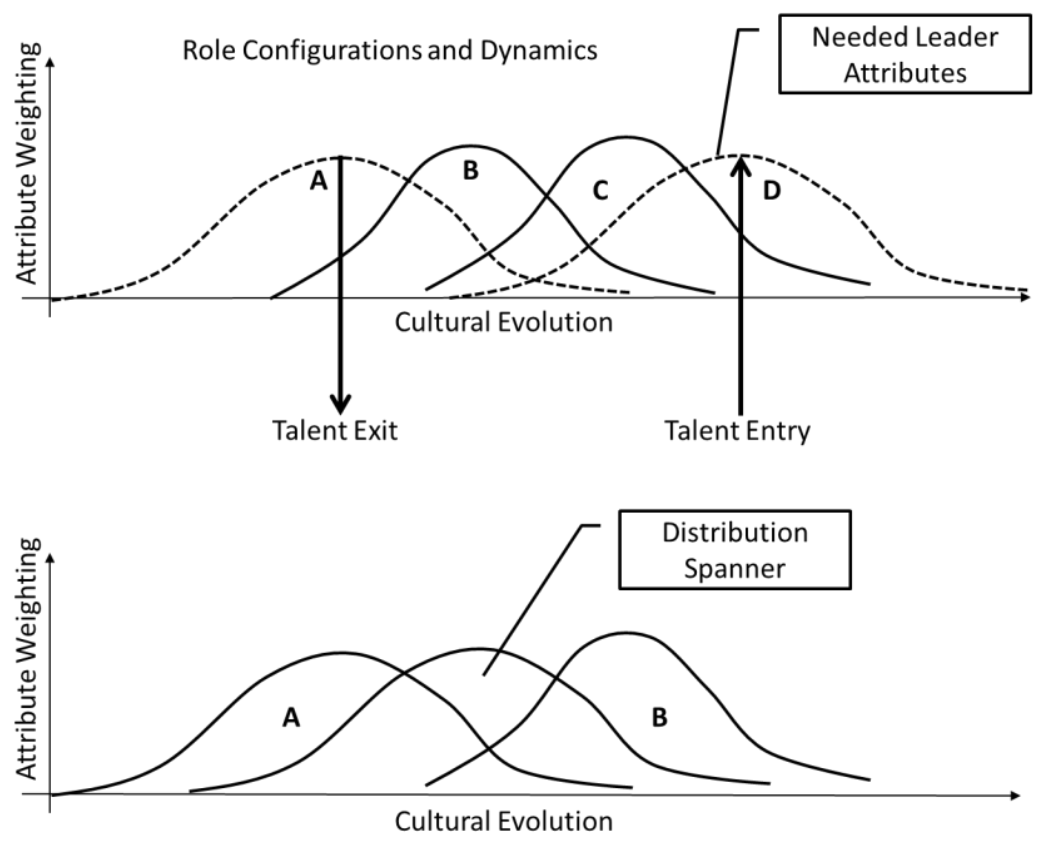

Figure 6. Talent placement for distribution phase shifting. This figure illustrates the positioning of talent and the relevance of spanning to leverage available talent complementarity.

Linking new cultural norms to existing ones that are similar may allow for easy wins in a transformation. The weighting of norms will provide context regarding the extent to which collateral damage is acceptable when linking is difficult. For example, the norm of continuous improvement may, or may not be, embraced; however, this attribute may be weighted high in the distribution of the to-be adopted culture. Ethno-geographic attributes may assist or inhibit such a norm, and so attributes from a local environment should be considered in light of the intended organization such that context for the shift may be more easily communicated. Higher levels of cultural meta-cognition allow a leader to navigate the transformational roadmap to an aligned and desired position. Cultural metacognition coupled with situational awareness allows multi-cultural competence to be dynamic and systemic. For example, an emerging demographic in India is referred to as a dinc (double income no children). This social dynamic creates tension in and of itself within a culture that has been family oriented. Tensions within national conflicted norms come to bear on organizationally imposed norms. For example, needless tension with dinc's may be created in an organization that refers to itself as family oriented. Communication patterns, among others, should therefore be altered to optimally influence or achieve objectives. Broadly, an aware leader may need to navigate across a cultural topography from one point to another as reflected in Figure 7. The roadmap may not be a straight path, but rather a series of incremental changes that represent optimal navigation to a desired state. 

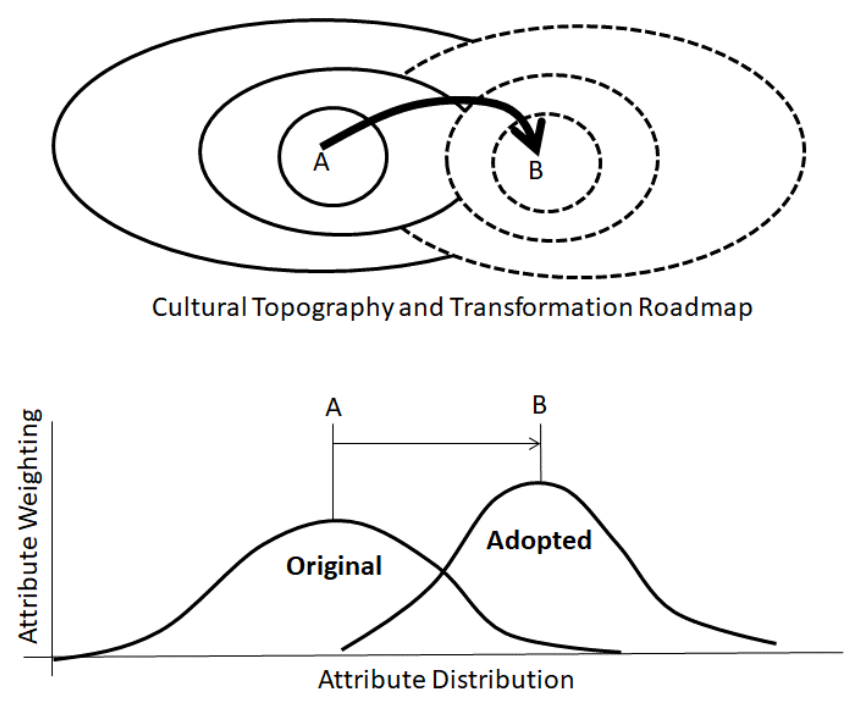

Figure 7. Culture shifting navigation. This figure illustrates the road map from the original organizational distribution to the vision based adopted distribution in a top and side view.

To move the company from A to B the leader may need to shock the culture to achieve the objectives in mind, while accepting any resultant collateral damage. Or, a leader may determine a roadmap of transformation that alters the current distribution of attributes (deprogram the culture as some attributes may become unnecessary) and take a number of steps along a path (reprogram the culture with attributes that are necessary) that ultimately allows the organization to achieve its new cultural schema without an unacceptable negative residual effect. A respect for cultural complexity may influence the leader's decision-making and the associated results. Furthermore, and generally, the differences between individuals and cultures may be lessened proactively by cultural blending, the sharing of best practices, and the proliferation of a common business language (Carbonell\& Rodríguez- Escudero, 2016).

\section{CASe STUdY}

Signal Corp, as a leading distributor of media-based assets, has operations that cover world-wide markets. It has a dominant market position in an industry subject to aggressive competitors and technology transformations. Consequently, SignalCorp must leverage and align the capabilities of its diverse talent across the globe. This MNE has discovered that decentralized collaboration includes diverse yet cooperative design elements, like incentives, alignment structures, and strong integrative mechanisms, with design elements that include strong local financial controls. The result is a constructive self-interest that balances stability and flexibility. An entrepreneurial ethos is global and decentralized, and so is supported by organization design. The roles within the global organization include line of business (LOB), geographical, support, and client oriented leaders. Collaboration is a norm that results in effort optimization by leveraging synergies rather than accentuating differences. Support structures enhance and align collaborative capabilities. Strategic methods are typically categorized into two focus areas:

- Growth strategies: Actions intended to increase revenue and profitability.

- Market penetrators: Actions intended to break through silos enabling growth.

Collaborative capability is supported by integrative support structures. In this case, data was collected from diverse stakeholders to identify alignment structures and their effectiveness during a designed interview process. The variety and influence of the integrative structures in a diverse global structure was significant. Regardless of the vantage point of the stakeholder, LOB leaders used this scaffolding to discover opportunity and make sure that their operations did not drift from gains achieved. After all, organizational entropy is especially present during the distraction of growth cycles (Levins, 1968).

The selection of diverse multi-cultural talent that is then placed in key roles is critical to collaboration and organizational success. The roles of leaders at SignalCorp were determined by their understanding of a vision, their ability to self-reflect on leadership attributes, their ability to make sense of cultural diversity, and their ability to execute in focused areas of impact. Regardless of their cultural vantage point, each stakeholder determined that certain leadership attributes would be needed 
in order for a leader at Signal Corp to be successful. These leaders related collaboration to a variety of job responsibilities indicated in the raw data.

"[We needed to] work closely with facility leaders worldwide, to improve business metrics and operational data (lowering costs, increasing throughput, higher quality, etc.) on [the] product line by transforming the way we perform various [LOB related] services."

"[We] work in tandem a lot with large orders or launches..."

"Coordination and influence of [system] development will be more effective and efficient if we stay aligned with our priorities."

"[We will] encourage partnerships between business units, to better utilize existing capacity."

Data was also collected from other stakeholders. The scope of the role-based data included P\&L leaders in all parts of the organization, including (a) LOB leaders, (b) geographic leaders, (c) support leaders, and (d) client-facing leaders. Some practical and tactical examples of measureable collaboration are related to several themes; system effectiveness, standardization, capacity management, and communication. The evidence of the positive impact of complimentary diversity, successfully applied, is found in the overall financial performance of the organization.

\subsection{LOB Themes}

LOB leaders were defined as leaders with responsibility for any aspect of a product or service category through direct contact with an asset or a deliverable (Van Wart \&Kapucu, 2011). The functions within this scope were all production areas, asset handling, configuration changing, and invoicing. Table 1 illustrates the critical themes in the coded data collected from participants who provided data on 17 aligning themes and 267 rich data descriptions with regard to their role and the roles of their peers regardless of location. This data explains what the participant leaders learned about alignment mechanisms and what they would need to focus on in order to successfully execute their responsibilities and be an effective leader. The first five will be discussed after the table as they represent $58 \%$ of the data population.

Table 1. Horizontal Role Attributes by Category

\begin{tabular}{|l|l|}
\hline \multicolumn{1}{|c|}{ Theme Category } & \\
\hline System Effectiveness Count \\
\hline Capacity Management & 40 \\
\hline Cost Reduction/Control & 33 \\
\hline Standardization & 31 \\
\hline Communication & 26 \\
\hline Revenue & 24 \\
\hline Performance/Reliability & 21 \\
\hline Leadership & 17 \\
\hline Strategy & 14 \\
\hline Financial & 11 \\
\hline Problem solving & 10 \\
\hline Knowledge & 8 \\
\hline Security & 7 \\
\hline Best practice Sharing & 7 \\
\hline Asset Management & 6 \\
\hline Transparency & 5 \\
\hline Organizational Culture & 4 \\
\hline Total & 3 \\
\hline
\end{tabular}

\subsection{System Effectiveness}

Transparency is enabled through the use of an organization-wide business system. This supports a decentralized approach as leaders can directly contribute to the profitability for which they are accountable and their success can be seen and exploited by other functional units. The ability to exploit the complementarity between units is augmented and encouraged by the transparency provided by the culture agnostic enterprise resource planning (ERP) system. Consequently, the first category in the role theme data table relates to the ERP system. It is no surprise that leaders who 
influence multiple facilities in different areas of the world value an ERP system that enables them to see what is happening at all locations, simultaneously. Without a system, the actual diversity between locations could not easily be understood and change management becomes very difficult. The raw data suggests that the overall concern is the ability to use the system consistently. This is critical such that production data are entered correctly with the consequent benefit of the exploitation of that data. The raw data in this case study suggests that leaders have six areas of concern that when achieved will ensure alignment: (a) that existing departments are using the system correctly, (b) that new modules become available for critical workflows that exist or may be deployed, (c) that other departments in the supply chain are brought into the system, (d) that other disparate systems are supported or integrated, (e) that development efforts are optimized, and (f) that tools are developed as appropriate and timely. The majority of the workers contribute to data in the system. Even though they perform different functions in different places, the system is a mechanism of transparency that enables an alignment of purpose the efficacy of which is dependent on capability. To illustrate, further detail in the data suggests that existing departments may need training before they use the system. Furthermore, leadership commitment to the system is also necessary for the transition.

"[We need to] partner with local teams to coordinate deployments and enhancements of [the] ERP for [product] pipeline services."

I will be joined at the hip on security/chain of custody issues. This area is getting more significant all the time and we need to make sure the worldwide facilities are unified in terms of compliance and process. We also need to work together on making the ERP [LOB] management functions so they properly track assets for all our facilities.

"[Leaders need to] be a hub to communicate with each facility and prioritize internal/ external client enhancement request. When [a] global enhancement is being deployed, communicate with the each facility beforehand to incorporate requests from individual facilities."

"[Leaders need to] assist in rolling [the ERP] out to our other locations."

"[The] coordination and influence of ERP development will be more effective and efficient if we stay aligned with our priorities."

"Migration to the ERP will also be a big area for [LOB] and it needs to be done as a coordinated effort and leveraging [name] experience with business systems."

[Leaders can] help me push projects like the implementation of a physical source retention policy for all sites so vaults do not fill up with material and increase storage needs/costs. [This] could include helping push the ERP enhancement to include 'source return date,' implementation of new policies in Client Services.

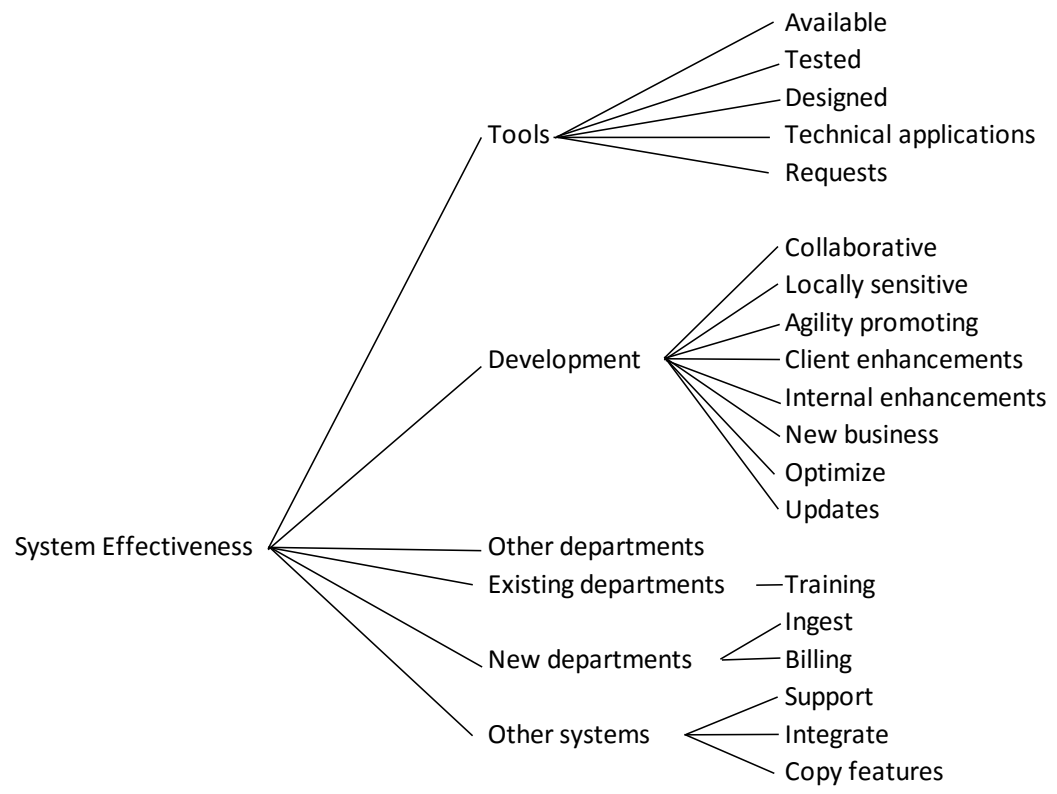

Figure 8. System Effectiveness: Consistent usage theme map. This figure maps the consistent usage of the ERP as a theme category into descriptive sub-groupings. 
A system, continuously in the improvement-deployment cycle, is necessary for the role of a horizontal leader in a global organization with responsibility over multiple facilities. A diverse work force sees opportunities for system usage that is built into the design, and so can be shared. Figure 8 illustrates the theme dependencies in the data. The coding path for the data map below starts with the theme category, then goes to the theme attribute, and then to the raw data theme.

\subsection{Capacity Management}

Horizontal leaders in the MNE indicated, by way of the second most frequently cited category, that management of capacity is critical to their role. The need for coordination of capacity on a global scale is critical to the success of business units that are constrained by resources being allocated to a business with extreme swings in capacity demand as illustrated in Figure 9. This business advantage relates to sustained profitability as local markets often offer up revenue opportunities that are beyond the capacity of the local facility, either by volume or type, which may be followed by times of very low volume. Unique markets offer up new opportunities that can be shared with other business units. A significant concern of the businesses is the ability to sell any product to any market size using the strength of the organization as a whole. Load balancing allows opportunities to be seized without damaging the business unit or the relationship with the client. The interaction between the business units and the local workers becomes critical to sustained corporate advantage. The raw data suggests that the overriding concern here relates to the ability to utilize global capacity on-demand in accordance with the local work load.

\section{"[Leaders] enable SignalCorp...facilities WW to leverage one another as a 'globalized" capacity to enable load balancing, service flexibility, [and the] capture of 'limitless' customer demand." \\ "[Leaders] determine the needs of each local facility in ... production and level of support required." \\ "[Leaders] work closely with facility leaders worldwide, to establish effective load balancing and off-load methods to eliminate capacity constraints in local offices."}

The desirable attributes of capacity availability are (a) scalability, (b) local availability, (c) strategic planning, and (d) the appropriate allocation of capacity. Capacity management is directly linked to meeting client expectations and profitability. A one-ness, an element of the organizations ethos, is experienced both internally between business units and externally as the customer experience success from their vendor. This ability to synchronize and deliver offers the aligned organization a competitive advantage over those organizations that cannot perform in this way.

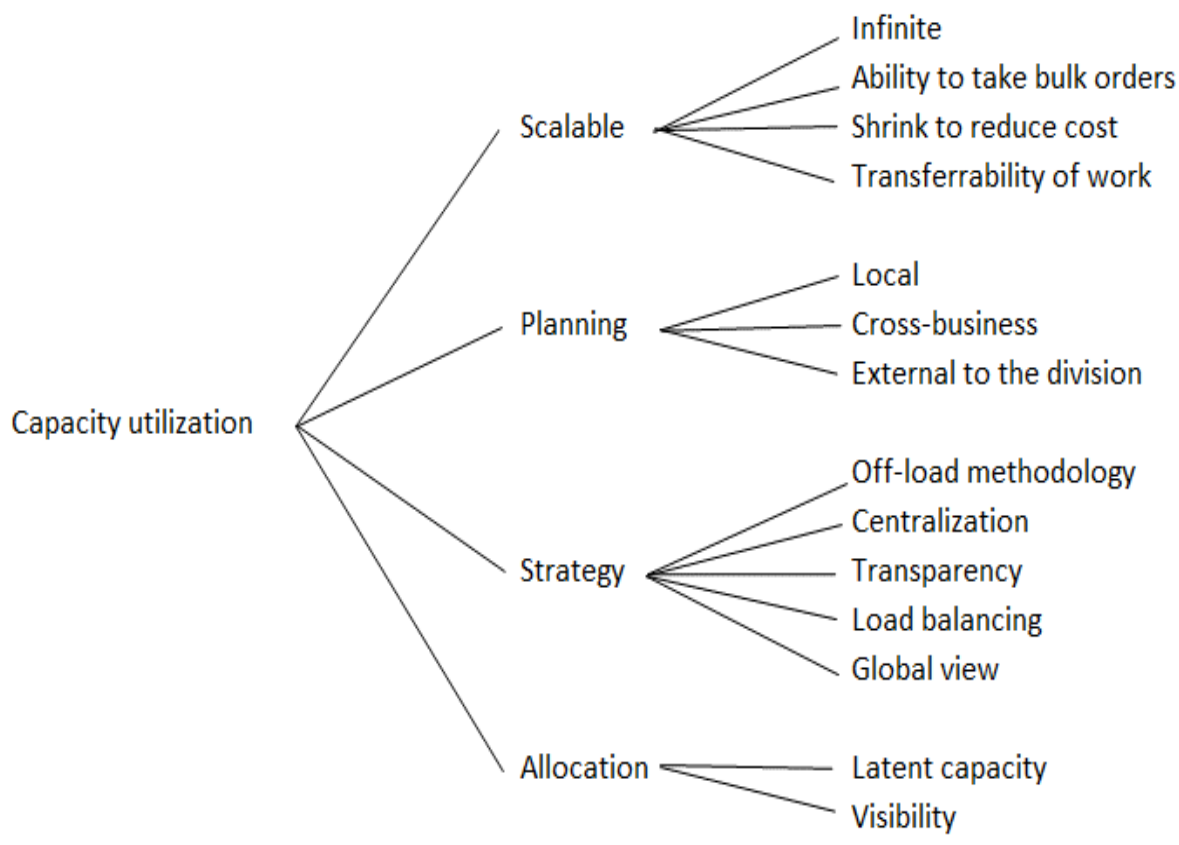

Figure 9. Capacity utilization theme map. This figure maps capacity utilization as a theme category into descriptive sub-groupings. 


\subsection{Cost Mitigation}

The third category within the LOB role attributes relates to cost management. Profitability relates directly to cost efficiencies and mitigations in a dynamic environment. Existing and growth-oriented revenue needs to be fulfilled in the most efficient way possible. These efficiencies have the follow-on effect that leads to the ability to increase production capacity with minimal incremental cost thereby creating the opportunity to increase market share. Diverse perspectives on capabilities and efficiencies can be harvested in local business units and shared for global impact as applicable. This integration of diversity helps a global leader understand and manage cost so that the organization can exploit growth synergies as illustrated in Figure 10. The desirable attributes of cost mitigation are (a) measurement, (b) waste reduction, (c) workflow efficiency, (d) centralization, or pooling resources, and (e) workflow alignment.

"[I] drive various cost savings initiatives, locally and globally, in regard to stock purchasing, courier and freight services, and off-site media storage."

"[I] increase LOB profits by creating efficiencies and lowering costs within the operation."

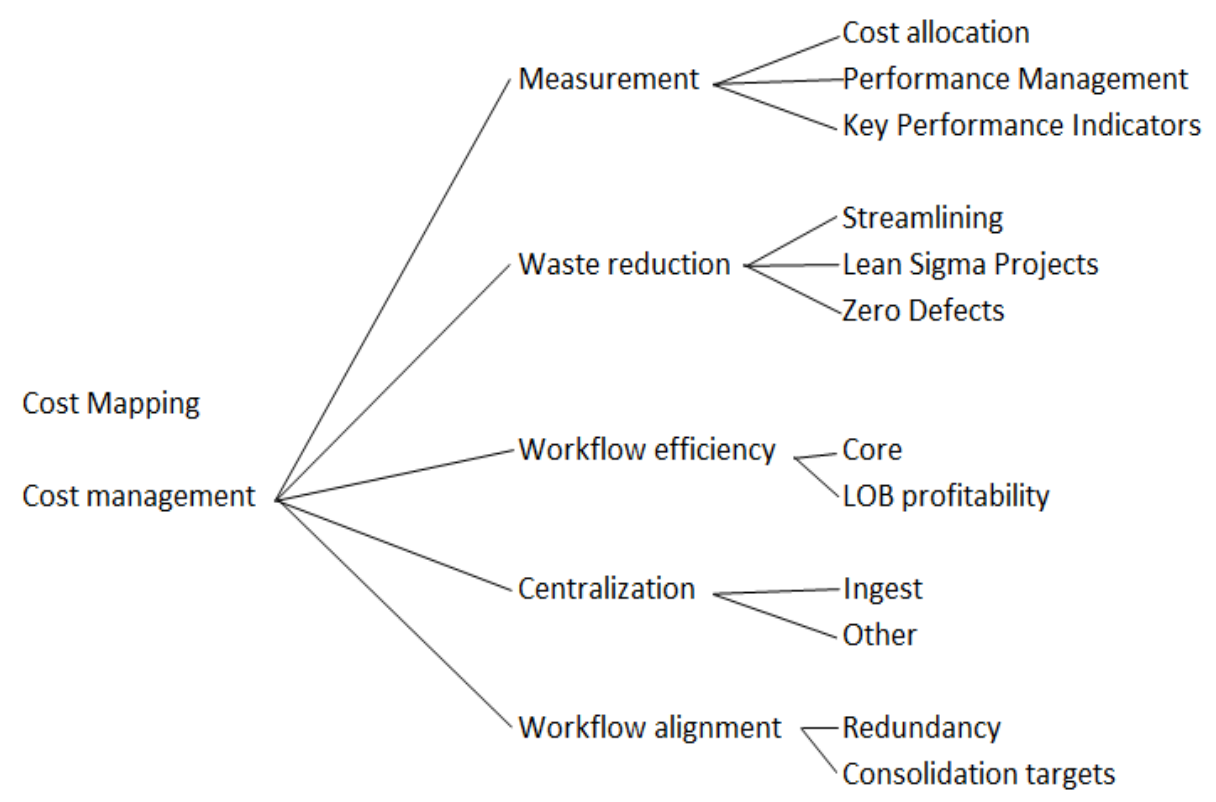

Figure 10. Cost mapping and management theme map. This figure maps cost mapping and specifically cost management as a theme category into descriptive sub-groupings.

\subsection{Standardization}

The fourth category relates to activities concerning unity and consensus. Leaders brought up standardization as it ensured performance through the reduction of complexity. In a chaotic environment, the enhancement of predictability is desirable for financial and capacity forecasting accuracy. The beneficial attributes of capacity availability are (a) unification, (b) workflows, (c) scalability, (d) data efficacy, and (e) predictability.

"[I will] establish [location] as a center of excellence for... workflows through bi-directional visibility, process alignment, and procedural standardization."

"[I will] partner with local leaders to drive unification, standardization, centralization, and operational efficiencies across key WW locations."

The data suggested that standardization as illustrated in Figure 11 is made possible in workflows through the deployment of work instructions and procedures that guide the activities in the operation. Standardization encourages alignment and enables capacity sharing between units. It assures excellence across all units as standardization is based on best practices. In general, excellence is pursued effectively through diversity of thought. Excellence, once discovered and matured can influence global operations. This standardization is then possible with inputs and outputs that have meaningful specifications that are universally known or easily transferable. The data suggested that scalability is important for, and a constraint of, growth. The data also suggested that standardization 
enables the use of metrics. Without metrics, an operation cannot assess its performance status. Finally, the data suggested that predictability is a benefit of standardization that enables accurate and profit bearing pricing, the creation of tools, and consistency.

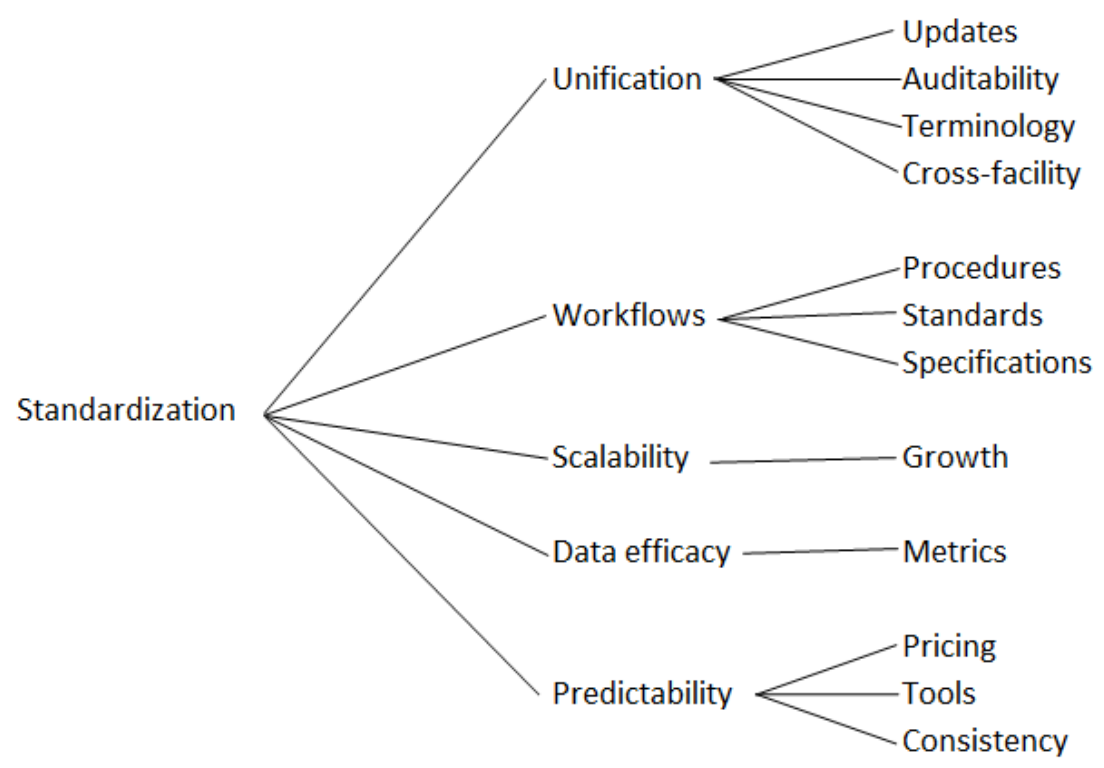

Figure 11. Standardization theme map. This figure maps standardization as a theme category into descriptive sub-groupings.

\subsection{Communication}

The fifth category of interest within the leadership roles in an MNE relates to communication. While communication is often cited as a reason for issues, its significance is typically underestimated. Unbelievable communication may create cognitive dissonance and frustration. Dissonance could occur when logic, opinions, and environmental knowledge are inconsistent (Festinger, Riecken, \&Schachter, 2008). Leaders need to exchange information that would result in dissonance reduction. Furthermore, there is an optimal level of communication that, when exceeded, is ignored. When minimized, it creates an information vacuum that breeds insecurity and frustration. A multi-cultural global leader understands the optimal way to communicate, recognizing that execution is local and situational. The data suggests that the desirable attributes of communication relate to (a) plans, (b) transparency, and (c) the method used.

"[I] establish cohesion and strategy of inter-facility operations, and unify best practices among ... WW ... facilities through free-flowing communication."

"[I] establish lines of communication between [support functions] encouraging cooperation and streamlining intercompany transactions."

The results suggest a structured communication plan approach that includes a deployed escalation plan, a single point of contact, periodic communication, and a flow of information. These elements help to optimize the interaction between critical units in the organizational system. There is also an optimal level of transparency that should be achieved through the communication strategy. Leaders required that there was the ability to be transparent about policies and capabilities. They wanted a common terminology to enhance communication efficacy. The data suggested that communication needs to be routed to a business unit, across business units, to a client, or to a vendor. While routing is important, transparency provides information about policies, capabilities, and includes terminology that is understandable both internally and external to the business unit. The data suggested that the method chosen is relevant. Leaders need to be able to hold a presence and communicate clearly oneon-one and in a video conference event, as applicable. The importance of one-on-one communication should not be underestimated. The ability to read cultural perspectives and react to body language may be critical to both maintaining attention and guiding thought patterns. The rate at which an organization or individual is influenced may depend significantly on face-time and their base position. To be successful in achieving growth synergies a leader needs to be an effective communicator both internal and external to their assigned organization as illustrated in Figure 12. 


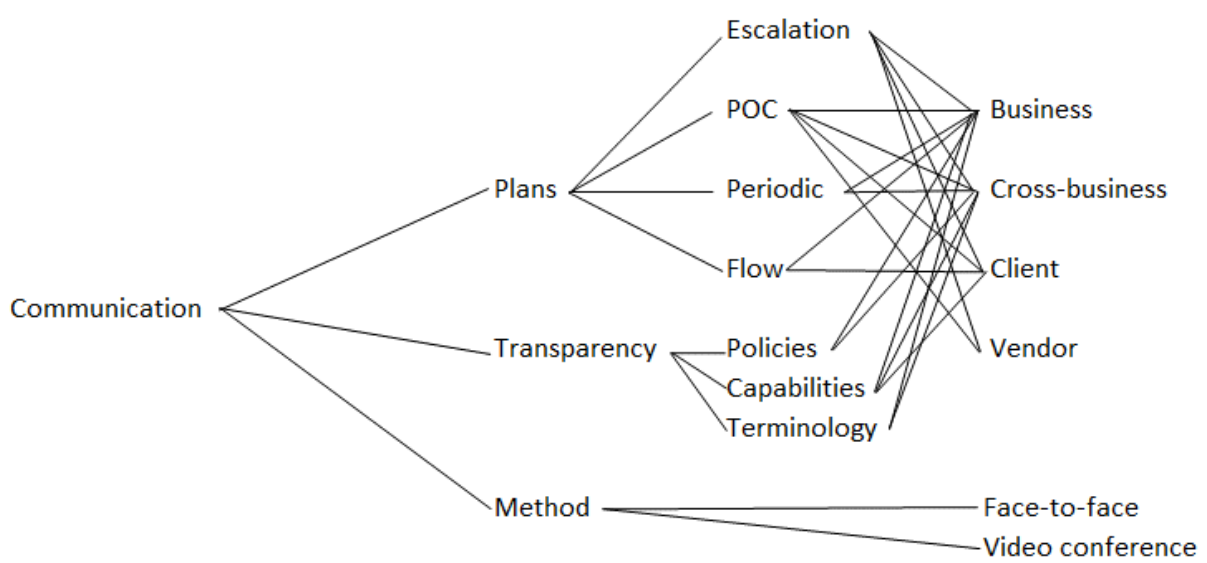

Figure 12. Communication theme map. This figure maps communication as a theme category into descriptive sub-groupings.

"II] work closely with facility leaders worldwide, to develop and implement organizational communication plans for effective communication between all key [operational] groups in WW [LOB] operations."

"[I will do a] better job of interacting across all SignalCorp departments in communicating difficulties in working with certain formats and/or advising easiest way to proceed with [workflows] when multiple options exist."

The complexity of these strategies should not be underestimated. Not only does the strategy include content, but it also includes frequency, audience, volume, method, and consideration for the local market climate. A global leader needs to be able to correctly plan for each of these variables. In addition, the leader needs to determine the optimal method for delivery of the content.

\section{FINDINGS}

Positive organizational scholarship (POS) can show how the lack of cultural driven friction can positively influence work life and performance. To mitigate the potential inertia from this friction, leaders must understand diversity within their organizational systems. It starts with employees, who are able to deal with obstacles through dedication and persistence, and who can handle conflict, have a positive mental outlook and are resilient enabling positive outcomes. The author challenges the 'illusion of discordance', along with other illusions and assumptions, by showing that it does not have to be this way. Culture is complex, intangible, and subtle but can be exploited uniquely to produce significant positive results. The author has shown how leaders and other stakeholders can get over the hurdles that are thought to be related to cultural distance, the extent to which different cultures are similar or different, through alignment structures and cultural intelligence. In many cases, an MNE will experience agency costs that are higher where there is cultural distance. This cost may also be influenced by the collateral damage from cultural collisions due to misapplied control tactics. The ability to close cultural distance through alignment and structure is possible by exploiting complementarity within an optimized diversity of skills and attributes, thereby mitigating some of these waste-oriented costs.

Diversity is an opportunity, a resource, and a catalyst for positive organizational change by exploiting positive deviance, virtuousness, and by endorsing a strengths-based orientation (Cameron, Dutton, \& Quinn, 2003; Clifton \& Harter, 2003; Dutton \& Ragins, 2006; Gittell, Cameron, Lim \& Rivas, 2006; Ely \& Thomas, 2001; Spreitzer \& Sonenshein, 2003). The result of exploited complementarity is an increase in ideation, productivity, and performance (Earley \& Masakowski, 2000; Ely \& Thomas, 2001; Polzer, Milton, \& Swann, 2002; Swann, Kwan, Polzer, \& Milton, 2003; Watson, Kumar, \& Michaelson, 1993). Should the salience of differences be minimized, or identified and exploited? The authors posit that diversity is salient and an important ingredient in a multicultural environment. Pretending that culture is neutral or homogenous tends to favor the dominant culture thereby creating an exclusionary approach to diversity (Markus, et al., 2000). Rather, these and other differences should be seen as a source of strength needed to achieve positive results (Cox, 1991). Organizational constructs that embrace differences are attractive to employees with diverse backgrounds because these differences are valued (Plaut\& Markus, 2007; Purdie-Vaughns et al., 2006; Verkuyten, 2005). 
Employees need a positive affirmation of their belongingness in an organization (Baumeister\& Leary, 1995). Diversity applies to all employees in a similar way, as everyone is different. While employees should be hired to perform a task with a look to the future, differences are a part of the package and should be desired based on their potential positive contribution. Overall inclusion is critical to gain the support of all members of the team/organization, rather than creating animosity because a certain group is preferred over another. Identity safety allows team members to strengthen their connectedness to the organization with confidence, and the opportunity to flourish (Markus, et al., 2000). Actors within any role configuration must move beyond the surface level tactics that display appreciation for diversity and social categorization, and rather inspire individuals to integrate diversity into the success of organizational objectives (Davidson \& James, 2006; Thomas \& Ely, 1996). High quality relationships based on respect and trust among those who are dissimilar can engender a positive effect, encourage ongoing learning, and create resiliency. It creates the capacity for individual engagement, the meeting of challenges, and the creation of a support structure that is unique and powerful where individual differences are valued rather than ignored (Davidson \& James, 2006). Affirming individual identity and recognizing unique characteristics encourages inclusivity in organizational contexts where interaction is required for effective coordinated action, efficient knowledge transfer, and organizational economic vitality (Nahapiet\&Ghoshal, 1998; Cameron \&Caza, 2004; Dutton, 2003).

A focused and aligned culture, regardless of existing cultural fragmentation, is needed for the organizational effectiveness. Gaps between the existing and the future culture need to be closed. One transformation roadmap will have a longer path than another implying that the survivability risk is higher for the culture that is furthest from the vision. This may also depend on hurdles to be overcome. On the other hand, the hurdles or cultural differences may not be as big as they appear. For example, Tibetan monks have iPhones and Maasai shepherds share music using blue-tooth technology. To illustrate further, a jazz band needs an assortment of instruments to be played by skilled musicians working together to make music that they think is good. The roles of each diverse member of an organization should be seen as both diverse and significant, but not static. The environment continually shifts and roles change. In a snapshot in time, there is capability and diversity, and yet complementarity, that when leveraged can influence success at that time. Structural aligning components that scaffold activities are a unifying factor that enhances the complementarity of talent.

\section{ILLUSIONS AND ASSUMPTIONS}

A number of illusions exist, and assumptions have been made regarding the implications of cultural distance. The author suggests that openness to cultural differences that can influence positive outcomes is a leadership attribute that may lead to positive outcomes. Cultural difference should be considered individually without assuming that geographical proximity will result in more or less difficulty. An appropriately connected global organization augmented by appropriate alignment mechanisms can help assure the ability of an organization to control and monitor all locations regardless of distance. Again, the selection of leadership with multi-cultural capability able to enact suitable culture distribution shifting may have an impact on the performance of a diverse workforce. Leaders with multi-cultural transformational success are better able to accomplish the complex task of alignment as they understand the structures and tend to respect differences more than mono-cultural leaders. The closing of the gap, organizational acculturation, is defined by Berry (1980) as changes resulting from the bi-directional diffusion of cultural elements.

Cultural agility suggests that acculturation can be executed predictively by actors that are culturally intelligent. Capable leaders anticipate the need to make adjustments prior to engaging in a new situation. Success may also be accomplished organizationally prior to the merging of two distinct groups. A cultural attractiveness bias may result in a relationship with an unexpected cultural gap that is just as difficult to remedy as gaps in cultures that appear to be distant. Furthermore, employees from the parent firm may bring to affiliates cultural elements that successfully merge or create dissonance with the existing culture. The impact of these elements may not be known until contact between the respective attributes happens. Leaders with multi-cultural capabilities are better able to understand potential collisions and create the culture needed for the relationship to move into the future. When a leader exploits organizational complementarity proactively in a dynamic environment a sustained competitive advantage is achieved. This ability to move forward is affected by cultural 
inertia. Friction, or organizational drag, is produced from collisions and the directional dissonance it creates. It is better that energy is diffused into activities related to creating alignment and deculturation, if routines must change. While differences are being resolved the salience of geographic cultural attributes are more visible requiring targeted attention.

\section{CONCLuSion}

Multinational enterprises exist to achieve innovation, global integration, and local differentiation in a world-wide context in order to perform and compete successfully (Bartlett \&Ghoshal, 1989; Nohria \& Ghoshal, 1997). A multi-cultural team is where two or more geographical cultures are present in the team (Adler, 1997), however culture is more complex in that organizational and personal culture are just as relevant. MNEs that seek to exploit global markets use multi-cultural teams because they promote flexibility, responsiveness, and an improved use of resources by leveraging global talent to meet the dynamic demands of global business environments. The organization's capabilities within each local business unit may migrate when the market evolves or is transformed to a new position resulting in the registration of demand. Does this suggest that diversity is a source of friction or a lubricant in an organization? Multi-national teams assembled locally and connected globally can have the ingredients needed for accelerated objective realization by exploiting complementarity. Furthermore, a lack of equilibrium may result in increased agility as the energy needed to make a change may be less. To reflect the MNEs intent to be global top leadership teams have become more multi-cultural, occasionally with the top position being occupied by someone from another geographical location. The many attributes represented on a diverse team allow for a team configuration that is meaningful regarding objective realization. These realizations are linked to the organizations performance scorecard and the achievement of opportunity potential in the market. Gibson and Cohen (2003) suggested that team effectiveness is driven by shared understanding, integration, and mutual trust. The author would add that a bias for action, an entrepreneurial capability, the ability to innovate, and a willingness to successfully compete are also relevant to the success of diverse teams.

Taking this further, while in some cases team members prefer to communicate with people like themselves, a strong curiosity drives team members to understand diverse perspectives. Even so, in some cases, barriers may be insurmountable and an accommodation is necessary. Many challenges can be met with strategies to solve the problems. These strategies may come from diverse perspectives. The free flow of ideas may require a recalibration of attitudes as a lack of trust may contribute to inertia. The correct representation of attributes should be linked to team member assignment allowing for optimal change velocity. Just as top leaders should be hired based on the company's vision, so can multi-cultural teams be assembled based on the attributes that match a vision. In some cases external selections help internal teams be less dependent on legacy routines. In other cases internal team members know the routines that need to be changed. A specific role in a team is defined by the exhibition of behaviors that are interrelated with the repetitious activities of others and the attributes of a person in a particular setting (Biddle, 1979; Katz \& Kahn, 1978).

Multi-cultural team members and leaders, if appropriately selected, can help teams in a global production network (GPN) more effectively relate to their new context, and help them problem solve their way there. They are more effective at helping these teams recalibrate their behavior distribution to the distribution needed in the new world than a single culture approach would. Teams with multicultural membership can build shared understanding, integrate, and create mutual trust because they respect the complexity in multi-cultural contexts and they know where they are going. Cultural metacognition enables key actors use inductive and analogical skills to step beyond their existing paradigms and be aware, so that they can adapt with agility. Team effectiveness is further enhanced by a resistance to make quick judgements regarding cultural norms.

While individual attribute distributions are relevant to team effectiveness, role configuration reflects the collective interactions of the team (Kozlowski \& Klein, 2000). For example, an intermediary, or distribution spanner, may be needed between two or more culturally divergent groups to exploit common ground as illustrated in Figure 6. They may also help to be the bridge between the current organizational culture and the necessary new context thereby preserving the team's effectiveness. Dynamic interacting dimensions may be destructive or, preferably, constructive depending on how they are managed, as an example. This technique may be applied to group design and alignment structures both to promote cohesion and to liberate ideation. The resultant complementarity allows the 
team to acquire resources, status, and information that other teams may not be able to. Openness to diversity allows for innovative thought, directional due to alignment mechanisms, to be the objective of the team rather than the self-interest of a few.

Multi-cultural leaders may also be more adept at obtaining knowledge from external sources enhancing a team's capability for knowledge acquisition and the collective sense-making process. They also accelerate the early and ongoing integration of culturally diverse team members or subgroups by managing potentially disruptive verbal and non-verbal behavior. Conversely, the free expression of constructive ideas and verbal sparring over deep thoughts are encouraged. A team, or community of innovation, that can engage in this way feels as though their network is strong and dense producing a level of psychological safety, strength, and trust (Edmondson, 1999; Koster, Vos, $\&$ Schroeder, 2017). enabling further rigor without risk of relational conflict (Jehn\&Mannix, 2001). Team members are responsible for the impact of their own behavior while understanding the base behavior of team members, so as to exploit team diversity for the purpose of completing an objective. High quality relationships can be created across differences. Consequently, a multi-cultural team has a potential positive advantage over a mono-cultural team to foster positive organizational change provided that a suitable organizational approach is used (Stevens, Plaut, \& Sanchez-Burks, 2008).

\section{LiMitations OF THE STUDY}

This paper develops a novel perspective on the positive influence of diversity in a globally connected MNE. Cultural diversity can augment multi-national efforts and lead to increased profitability. Even so, there are limitations to this study that should be noted that require additional research. Furthermore, the tools presented in this paper are complex and dependent on a number of factors at any given time. We think that this research approach is promising and shows significant analytical potential; however, it may not be significantly or consistently generalizable. The scope of this case study is limited and needs further research regarding application in a variety of organizational and environmental circumstances. Even so, considering organizational history and impactful environmental trends, the research method described includes consideration for a significant number of variables that are in play at any given time. Consideration for these variables and the associated complexity of an ecological situation informs a complex picture of reality. Consequently, the themes extracted from the data may not be correctly delineated from each other. There is limitation associated with the scope of the case, especially given that the environment is constantly changing. The themes may have been inaccurately weighted, although in this case they were more mentioned rather than weighted. The environment could change as markets do. And, there is an actual linkage, or dependency, between themes that is not discussed. With these realities in mind, the researcher attempted to organize the data in such a way as to convey, in a most accurate and concise way, the findings generally inferred from the data. The researchers, based on their knowledge of the operation and their experience, made these judgments.

To be clear, any time bracketed study is subjectively interpreted based on an incomplete set of variables. Typically, an incomplete data set is available, and so we believe that the concepts and models presented provide a meaningful framework for an agile and robust method for research in a dynamic environment. Like any conceptual paper the primary limitation is a lack of empirical validation for the proposed models. As such, leaders should be cautious when implementing the conceptual models presented in our study. While this paper presents normative recommendations to leaders, much work remains to be done in this area of diversity research to expose the positive aspects of complementarity. We hope that our study informs and motivates further work on this important topic. I will also suggest that additional research is needed to understand this better.

\section{REFERENCES}

[1] Bartlett, C.A., \&Ghoshal, S. (1989). Managing across borders: The transnational solution. Boston, MA: Harvard Business School Press.

[2] Baumeister, R.F.,\& Leary, M.R. (1995). The need to belong: Desire for interpersonal attachments as a fundamental human motivation. Psychology Bulletin, 117, 497-529.

[3] Benet-Martínez, V., \&Haritatos, J. (2005). Bicultural identity integration (BII): Components and psychosocial antecedents. Journal of Personality, 73(4), 1015-1050.

[4] Berry, J.W. (1980). Social and cultural change. In Triandis, H.C., \&Brislin, R.W. (Eds.), Handbook of Cross-Cultural Psychology (Vol. 5, pp. 211-279). Boston, MA: Allyn \& Bacon. 
[5] Biddle, B. J. (1979). Role theory: Concepts and research.Malabar, FL:Krieger Pub Co.

[6] Cameron, K.S.,\& Caza, A. (2004). Exploring the relationships between organizational virtuousness and performance. American Behavioral Scientist, 47, 766-790.

[7] Cameron, K.S., Dutton, J.E., \& Quinn, R.E. (Eds.). (2003). Positive organizational scholarship: Foundations of a new discipline. San Francisco: Berrett-Kohler.

[8] Carbonell, P., \& Rodríguez-Escudero, A. I. (2016). The individual and joint effects of process control and process-based rewards on new product performance and job satisfaction. BRQ Business Research Quarterly, 19(1), 26-39.

[9] Clifton, D.O.,\& Harter, J.K. (2003) Investing in strengths. In K.S. Cameron, J.E. Dutton, \& R.E. Quinn (Eds.), Positive organizational scholarship: Foundations of a new discipline (pp. 111-121). San Francisco: Berret-Koehler.

[10] Costa, P.T., \&McCrae, R.R. (1992). Four ways five factors are basic.Personality and Individual Differences, 13(6), 653-665.

[11] Cox, T., Jr. (1991). The multicultural organization. Academy of Management Executive, 5, 34-37.

[12] Cox, T., Jr. (1993). Cultural diversity in organizations: Theory, research, and practice. San Francisco, CA:Berrett-Koehler.

[13] Davidson, M.N.,\& James, E.J. (2006) The engines of positive relationships across difference: Conflict and learning In J.E. Dutton \& B.R. Ragins (Eds.), Exploring positive relationships at work: Building a theoretical and research foundation (pp. 137-158). Mahwah, NJ: Lawrence Erlbaum.

[14] Dutton, J.E. (2003). Energizing your workplace: Building and sustaining high-quality relationships at work. San Francisco, CA: Jossey-Bass.

[15] Dutton, J.E.,\&Ragins, B.R. (Eds.). (2006). Exploring positive relationships at work: Building a theoretical and research foundation. Mahwah, NJ: Lawrence Erlbaum.

[16] Earley, P.C.,\&Masakowski, E. (2000). Creating hybrid team cultures: An empirical test of transnational team functioning. Academy of Management Journal, 43, 26-49.

[17] Edmondson, A. (1999). Psychological safety and learning behavior in work teams. Administrative Science Quarterly, 44(2), 350-383.

[18] Ely, R.J.,\& Thomas, D.A. (2001). Cultural diversity at work: The effects of diversity perspectives on work group processes and outcomes. Administrative Science Quarterly, 46, 229-273.

[19] Festinger, L., Riecken, H.W., \&Schachter, S. (2008). When prophecy fails. London, UK: Pinter \& Martin Publishers.

[20] Galbraith, J.R. (2000). Designing the global corporation. Hoboken, NJ: Jossey-Bass.

[21] Gibson, C.B., \& Cohen, S.G. (Eds.). (2003). Virtual teams that work: Creating conditions for virtual team effectiveness. Hoboken, NJ: John Wiley \& Sons.

[22] Gittell, J.H., Cameron, K., Lim, S., \& Rivas, V. (2006). Relationships, layoffs, and organizational resilience airline industry responses to September 11. The Journal of Applied Behavioral Science, 42(3), 300-329.

[23] Hofstede, G.H., \&Hofstede, G. (2001). Culture's consequences: Comparing values, behaviors, institutions and organizations across nations. Thousand Oaks, CA: Sage.

[24] Hofstede, G. (2011). Dimensionalizing cultures: The Hofstede model in context. Online readings in Psychology and Culture, 2(1), 8.

[25] Hoftede, G., Hofstede, G. J., \&Minkov, M. (2010). Cultures and organizations: Software of the mind: Intercultural cooperation and its importance for survival. New York, NY:McGraw-Hill.

[26] Jehn, K. A., \&Mannix, E. A. (2001). The dynamic nature of conflict: A longitudinal study of intragroup conflict and group performance. Academy of Management Journal, 44(2), 238-251.

[27] Katz, D., \& Kahn, R. L. (1978). The social psychology of organizations. New York, NY: Wiley.

[28] Kirchmeyer, C., \& McLellan, J. (1991). Capitalizing on ethnic diversity: An approach to managing the diverse workgroups of the 1990s. Canadian Journal of Administrative Sciences, 8(2), 72-79.

[29] Kluckhohn, F. R., \&Strodtbeck, F. L. (1961). Variations in value orientations. Oxford, England: Row, Peterson.

[30] Kluckhohn, C. (1962). Culture and behavior. Oxford, England: Free Press Glencoe.

[31] Klein, K. J., \& Kozlowski, S. W. (2000). Multilevel theory, research, and methods in organizations: Foundations, extensions, and new directions. San Francisco, CA: Jossey-Bass.

[32] Koster, M., Vos, B., \& Schroeder, R. (2017). Management innovation driving sustainable supply management: Process studies in exemplar MNEs. BRQ Business Research Quarterly, 20(4), 240-257. 
[33] Levins, R. (1968). Evolution in changing environments: Some theoretical explorations. Princeton, NJ: Princeton University Press.

[34] Markus, H. (1977). Self-schemata and processing information about the self.Journal of personality and social psychology, 35(2), 63.

[35] Markus, H.R., Steele, C.M., \& Steele, D.M. (2000). Colorblindness as a barrier to inclusion: Assimilation and non-immigrant minorities. Daedalus, 129, 233-259.

[36] Nahapiet, J., \&Ghoshal, S. (1998). Social capital, intellectual capital, and the organizational advantage. Academy of management review, 23(2), 242-266.

[37] Nohria, N., \&Ghoshal, S. (1997). The differentiated network: Organizing multinational corporations for value creation. San Francisco, CA: Jossey-Bass.

[38] Nowak, A., Vallacher, R. R., Tesser, A., \&Borkowski, W. (2000). Society of self: The emergence of collective properties in self-structure. Psychological Review, 107(1), 39.

[39] Polzer, J.T., Milton, L.P., \& Swann, W.B., Jr. (2002). Capitalizing on diversity: Interpersonal congruence in small work groups. Administrative Science Quarterly, 47, 296-324.

[40] Serrano-Bedia, A. M., López-Fernández, M. C., \&García-Piqueres, G. (2017). Complementarity between innovation knowledge sources: Does the innovation performance measure matter?.BRQ Business Research Quarterly.

[41] Spreitzer, G.M., \&Sonenshein, S. (2003). Positive deviance and extraordinary organizing. In K.S. Cameron, J.E. Dutton, \& R.E. Quinn (Eds.), Positive organizational scholarship: Foundations of a new discipline. (pp. 207-224). San Francisco, CA: Berrett-Koehler.

[42] Stevens, F. G., Plaut, V. C., \& Sanchez-Burks, J. (2008). Unlocking the benefits of diversity all-inclusive multiculturalism and positive organizational change. The Journal of Applied Behavioral Science, 44(1), 116-133.

[43] Sundberg, N. D., Snowden, L. R., \& Reynolds, W. M. (1978). Toward assessment of personal competence and incompetence in life situations.Annual Review of Psychology, 29(1), 179-221.

[44] Swann, W.B., Jr., Kwan, V.S., Polzer, J.T., \& Milton, L.P. (2003). Fostering group identification and creativity in diverse groups: The role of individuation and self-verification. Personality and Social Psychology Bulletin, 29, 1396-1406.

[45] Thomas, D.A., \& Ely, R.J. (1996). Making differences matter: A new paradigm for managing diversity. Harvard Business Review, 74(5), 79-90.

[46] Van Wart, M., \&Kapucu, N. (2011). Crisis management competencies: the case of emergency managers in the USA. Public Management Review, 13(4), 489-511.

[47] Verkuyten, M. (2005). Ethnic group identification and group evaluation among minority and majority groups: Testing the multiculturism hypothesis. Journal of Personality and Social Psychology, 88, 121-138.

[48] Watson, W.E., Kumar, K., \& Michaelson, L.K. (1993). Cultural diversity’s impact on interaction process and performance: Comparing homogenous and diverse task groups. Academy of Management Journal, 36, 590-602.

Citation: Joel Bigley. "Complementarity in a Digital Global Production Network: A Case Study" International Journal of Managerial Studies and Research (IJMSR), vol 7, no. 1, 2019, pp. 1-18. doi: http://dx.doi.org/10.20431/2349-0349.0701001.

Copyright: (C) 2019 Authors. This is an open-access article distributed under the terms of the Creative Commons Attribution License, which permits unrestricted use, distribution, and reproduction in any medium, provided the original author and source are credited. 